communication). Appleyard (1968) showed that babies born after an anoxic delivery developed a significant lowering of the Thrombotest at 24 hours compared with those who were not anoxic during delivery.

Possibly the lowered Thrombotest is associated with liver damage due to hypoxia; however, more probably the infants had some degree of disseminated intravascular coagulation resulting from the metabolic acidosis and hypotension associated with intrapartum asphyxia. The intravascular coagulation reduces clotting factors-including prothrombin (factor II), which is consumed-and this will be reflected by a lowered Thrombotest. Some intravascular coagulation undoubtedly occurs in anoxic babies during delivery, as fibrin split products are almost invariably found in the first day of life (M. A. Chadd and S. M. Muxworthy, personal communication). It is suggested that this may be the mechanism in some of the present series. We have several times encountered babies with low Thrombotest who have responded to a dose of fresh frozen plasma by a rise in Thrombotest, but the level has quickly dropned. Some of these babies have shown no sign of haemorrhage at necropsy, so that the rapid drop in factor II level can be explained only by a consumption coagulopathy. The fibrin formed during coagulation, if deposited in small end arteries throughout the brain, could cause multiple areas of cerebral ischaemia, which may explain some of our findings.

We wish to thank Professor Hubert Campbell for help with the statistics; Professor A. C. Turnbull for ever ready support; and the nursing staff of the Cardiff Maternity Hospital for their co-operation at all times.

REFERENCES

Appleyard, J. (1968). Neonatal Research Society.

Boyd, J. F. (1967). Archives of Diseases in Childhood, 42, 401.

Gray, O. P., Ackerman, A., and Fraser, A. J. (1968). Lancet, 1, 545

Gray, O. P., Ackerman, A., and Fraser, A. J. (1968). Lancet, 1, 545 . Press.

Sheridan, M. D. (1958). British Medical fournal, 2, 999

Sheridan, M. D. (1960a). British Medical fournal, 2, 453

Sheridan, M. D. (1960b). The Developmental Progress of Infants and Young Children. London, H.M.S.O.

\title{
Value of Prospective Tissue Typing in Kidney Transplantation between HL-A Identical Siblings
}

\author{
RAMON PATEL, ${ }^{*}$ M.B., M.R.C.P., M.R.A.C.P. ; STEVEN MYRBERG, ${ }^{*}$ B.A.
}

British Medical fournal, 1970, 4, 709-712

\begin{abstract}
Cummary: The predictability of leucocyte typing in kidney transplantation was assessed by an analysis of 37 kidney transplants from sibling donors. Recipients who were identical for the HL-A antigens with their donors gave highly predictable results. In comparison with those siblings who were incompatible or compatible but not identical their grafts functioned earlier, they required less immunosuppression, and had never had any rejections. They also appeared to have less postoperative morbidity. These results indicate that less immunosuppression than is current in many transplant centres could well be used with benefit in HL-A identical sibling transplants. This could reduce the risk of infection and possibly minimize the adverse effects of steroids on wound healing in these patients.
\end{abstract}

\section{Introduction}

Though kidney transplantation is now widely undertaken for certain patients with end-stage kidney disease, rejection and its sequelae continue to be major problems (Hume et al., 1966). Rejections are common during the first three months after transplantation and require large doses of immunosuppressive drugs for their control (Lee et al., 1967). As a result serious complications, including death of the patient, of ten develop in relation to a rejection episode (Starzl, 1964). In general, rejections tend to be less severe and fewer in recipients of bettermatched than in recipients of poorly-matched kidneys (Terasaki et al., 1967). At present HL-A matching is most precise and reliable in the selection of those sibling pairs who inherit the same HL-A chromosome from each of the parents and therefore have an identical HL-A genotype (Amos and Zmijewski, 1967). In our present study the high predictability of leucocyte typing in kidney transplantation between HL-A identical siblings was shown by the results of analysing 37 kidney transplants from sibling donors.

*'The Serotyping Laboratory, Departments of Medicine and Surgery, Peter Bent Brigham Hospital and Harvard Medical School, Boston, Mass.

\section{Materials and Methods}

Between 1 February 1966 and 15 May 1970, 41 patients underwent kidney transplantation from sibling donors at the Peter Bent Brigham Hospital. Of these, 37 were considered suitable for analysis. Three grafts which failed because of hyperacute rejection in sensitized patients and one because of technical reasons were excluded. Details of the surgical technique have already been described (Murray $\ddot{e t}$ al., 1968). All patients received azathioprine and prednisone as the basic immunosuppressive drugs. Sixteen patients received additional immunosuppression as follows: thoracic duct drainage in 5, thoracic duct drainage plus extracorporeal irradiation in 3 , thoracic duct drainage plus antilymphocytic globulin in 4, and antilymphocyte globulin alone in 4 . The drug dosage and the various immunosuppressive regimens (Tilnciy et al., 1970) were independent of the tissue match. Rejection episodes were treated with short courses of $200-400 \mathrm{mg}$. of prednisone which were rapidly tapered according to the response. A three-day course of actinomycin $\mathrm{C}$ was added in cases that responded poorly to prednisone.

Tissue typing was performed according to the microlymphocytotoxicity method of Terasaki and McClelland (1964), with allogeneic anti-HL-A typing sera kindly supplied by Dr. Paul Terasaki, of Los Angeles, California. Thirtythree patients were typed for 12-18 and four for 8 leucocyte antigens. Of the latter patients three died and one was living overseas, so that they could not be retyped with a larger panel of typing sera. At the initial typing, however, two of these patients were considered incompatible with their donors for the leucocyte antigen HL-A2, which even in earlier typings was the most accurately defined of all leucocyte antigens (Patel et al., 1969). A third patient was identical with his donor for three antigens as well as for a number of unspecified sera. Thus despite the fact that typings were done at different periods their accuracy is likely to be seriously questioned in only one of the 37 patients in this series. On the basis of the results of leucocyte typing, the following histocompatibility grades were assigned: recipient- 
donor identity, if both donor and recipient possessed the same HL-A antigens; recipient-donor compatibility, if in addition to having some antigens in common the recipient had one or more antigens not present in the donor; and recipient-donor incompatibility, if the donor had one or more. antigens not present in the recipient.

\section{Results}

The efficacy of leucocyte typing was assessed by comparing the following criteria between the HL-A identical, HL-A compatible, and HL-A incompatible transplants: duration of graft survival, early graft function, number of rejection crises, dose of immunosuppressive drugs, and postoperative morbidity. With respect to graft survival, either graft rejection or patient's death constituted a failure.

\section{Duration of Graft Survival}

Of the 37 patients 11 were identical, 8 compatible, and 18 incompatible for the HL-A antigens with their donors. There were six failures in the series-four in the incompatible group and one each in the identical and compatible groups. In the incompatible group two patients rejected their grafts one 41 and the other 270 days after transplantation, while a third died of septicaemia associated with rejection 59 days after transplantation. The fourth patient ruptured her graft during a rejection crisis in the first postoperative week but made an uneventful recovery, dying in an automobile accident 1,040 days after transplantation. The single failure in the identical group was a 43-year-old man who developed ureteric stenosis and had to be readmitted to hospital for surgical correction. Postoperatively, Gram-negative septicaemia ensued and he died 164 days after transplantation. Up to that time he had never had any rejections and had maintained a stable serum creatinine between 1.0 and $1.3 \mathrm{mg} . / 100 \mathrm{ml}$. The sixth patient who was compatible with his donor also died of Gramnegative septicaemia 199 days after transplantation. His early course, however, was complicated by two severe rejections (one of which resulted in a rupture of the graft), wound sepsis, and haemorrhage.

Among those patients whose grafts were functioning on 31 July 1970 the average survival of the 14 incompatible grafts was 743.7 days (range 77-1,359 days). This was longer than the mean survival for the seven compatible (549.7 days, range 105-1,227 days) and 10 identical grafts (497.5 days, range $105-1,607$ days).

\section{Early Graft Function}

The number of days required for the serum creatinine to fall from the :mean pretransplant value to a mean value of $1.5 \mathrm{mg} . / 100 \mathrm{ml}$. or less was adopted as a rough measure for the early graft function in each of the three categories of transplants. The mean pretransplant serum creatinine was comparable in the three groups: $8.3 \mathrm{mg} . / 100 \mathrm{ml}$. in the identical group, $7.8 \mathrm{mg}$. in the campatible group, and $8.8 \mathrm{mg}$. in the incompatible group. In the case of the $11 \mathrm{HL}-\mathrm{A}$ identical grafts, serum creatinine fell to less than $1.5 \mathrm{mg} . / 100 \mathrm{ml} .2$ to 12 days after transplantation in all patients, the mean fall being to a level of $1.2 \mathrm{mg}$. in 4.4 days. In contrast, 1 to 51 days elapsed before serum creatinine fell to $1.5 \mathrm{mg} . / 100 \mathrm{ml}$. or less in six of the eight patients in the compatible group (mean fall to 1.5 in 15.8 days) and 3 to 53 days in 13 of the 14 patients in the incompatible group (mean fall to $1.4 \mathrm{mg}$. in 16.5 days). Serum creatinine never fell below $1.6 \mathrm{mg} . / 100 \mathrm{ml}$. in two compatible and in one incompatible patients. This difference in the rate of fall of serum creatinine is significant for the HL-A identical and HL-A incompatible groups $(P<0.01)$ as well as for the HL-A identical and the combined HL-A compatible and incompatible groups

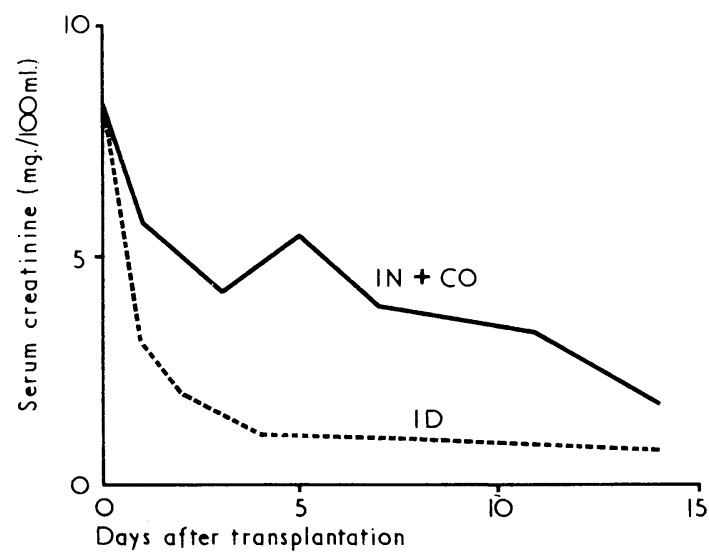

Serum creatinine in HL-A identical (ID) and HL-A incompatible (IN) plus HL-A compatible transplants during first two weeks.

$(P<0.01)$. Between the HL-A identical and HL-A compatible groups the difference fell short of statistical significance $(P=$ 0.05 to $\mathbf{0} \cdot 1)$. The difference between the HL-A compatible and HL-A incompatible groups was clearly not significant $(P>0.9)$. The Chart shows that during the first two weeks after transplantation the mean serum creatinine level remained consistently higher in the combined HL-A compatible and incompatible groups than in the HL-A identical group.

\section{Number of Rejection Crises}

Rejection was diagnosed on the basis of the accepted clinical criteria (Carpenter and Merrill, 1969). Twenty-five rejection crises were diagnosed and treated in these 37 patients. All but two occurred within the first three months after transplantation. The distribution of the rejections among the three histocompatibility grades is shown in Table I. None

TABLE I,-Distribution of Rejection Crises in 37 Sibling Transplants

\begin{tabular}{|c|c|c|c|c|c|}
\hline $\begin{array}{c}\text { Histocompatibility } \\
\text { Grade }\end{array}$ & & & $\begin{array}{l}\text { No. of } \\
\text { Patients }\end{array}$ & $\begin{array}{c}\text { No. with } \\
\text { Rejections }\end{array}$ & $\begin{array}{c}\text { Total } \\
\text { Rejections }\end{array}$ \\
\hline $\begin{array}{l}\text { HL-A identity (ID) } \\
\text { HL-A compatibility (CO) } \\
\text { HL-A incompatibility (IN) }\end{array}$ & $\begin{array}{l}\cdots \\
\cdots\end{array}$ & $\begin{array}{l}\cdots \\
\cdots \\
\cdots\end{array}$ & $\begin{array}{r}11 \\
8 \\
18\end{array}$ & $\begin{array}{l}0 \\
4(50 \%) \\
12(67 \%)\end{array}$ & $\begin{array}{r}0 \\
6 \\
19\end{array}$ \\
\hline Total $\ldots$ & $\ldots$ & $\ldots$ & 37 & $16(43 \%)$ & 25 \\
\hline
\end{tabular}

ID v. IN: $\mathrm{P}<0.001$. ID $v . \mathrm{CO}: \mathrm{P}-0.01$. CO $v . \mathrm{IN}: \mathrm{P} \cdot 0.3$.

of the $11 \mathrm{HL}-\mathrm{A}$ identical patients had ever experienced a rejection despite a total follow-up period of over 5,000 patientdays. On the other hand, four of the eight compatible and 12 of the 18 incompatible patients had one or more rejection episodes during the follow-up period. The number of rejections per patient in these two groups of transplants were similar (1.5 in the compatible and 1.6 in the incompatible group) The difference between the HL-A identical and HL-A incompatible transplants is highly significant $(P<0.001)$. The difference was reduced but still significant $(P<0.01)$ between the HL-A identical and HL-A compatible groups, while that between HL-A compatible and HL-A incompatible groups was not statistically significant $(P>0.3)$.

\section{Immunosuppression}

To exclude the possibility that more immunosuppression: might have been the factor responsible for the superior results seen in the $\mathrm{H}-\mathrm{A}$ identical transplants, we compared 
TABle II.-Comparison of the mean Daily Dose of Prednisone in mg./kg. Body Weight in Sibling Transplants According to the Histocompatibility Grade

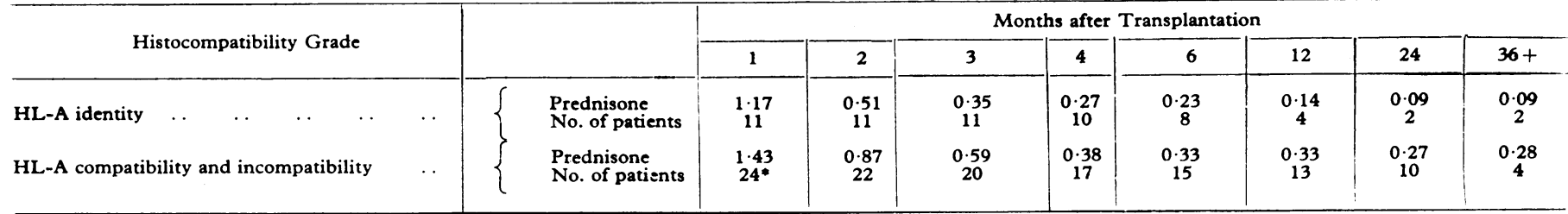

- Data not available for 2 patients. $P<0.001$.

the mean dose of prednisone (in $\mathrm{mg} . / \mathrm{kg}$.) between the HL-A identical group, who had no rejections, and the HL-A compatible plus HL-A incompatible groups, who had rejections. At all points in the postoperative period the identical group received less prednisone than the combined compatible and incompatible groups (Table II). This difference is statistically highly significant $(\mathrm{P}<0.001)$.

In addition it seemed important to assess whether or not any additional immunosuppression in the form of thoracic duct drainage, antilymphocytic globulin, and extracorporeal irradiation could have influenced these results. An analysis of the 16 patients who received this supplementary immunosuppression in addition to prednisone and azathioprine is given in Table III. Rejections still occurred in

TABLE III.-Analysis of 16 Recipients of Sibling Donor Transplants who had Received Supplementary Immunosuppression

\begin{tabular}{|c|c|c|c|c|}
\hline $\begin{array}{l}\text { Histocompatibility } \\
\text { Grade }\end{array}$ & Patient & $\begin{array}{l}\text { Immuno- } \\
\text { suppression }\end{array}$ & $\begin{array}{c}\text { No. of } \\
\text { Rejections }\end{array}$ & $\begin{array}{l}\text { Current } \\
\text { Status }\end{array}$ \\
\hline HL-A identity . . & $\begin{array}{l}\mathbf{A} \\
\mathbf{B} \\
\mathbf{C} \\
\mathbf{D}\end{array}$ & $\begin{array}{l}\text { T.D.F. + E.C.I. } \\
\text { A.L.G. } \\
\text { A.L.G. } \\
\text { A.L.G. }\end{array}$ & $\begin{array}{l}0 \\
0 \\
0 \\
0\end{array}$ & $\begin{array}{l}\text { Functioning } \\
\text { Functioning } \\
\text { Functioning } \\
\text { Functioning }\end{array}$ \\
\hline HL-A compatibility & $\begin{array}{l}\mathrm{E} \\
\mathrm{F} \\
\mathrm{G} \\
\mathrm{H}\end{array}$ & $\begin{array}{l}\text { T.D.F. } \\
\text { T.D.F. } \\
\text { T.D.F. + A.L.G. } \\
\text { A.L.G. }\end{array}$ & $\begin{array}{l}0 \\
2 \\
0 \\
3\end{array}$ & $\begin{array}{l}\text { Functioning } \\
\text { Functioning } \\
\text { Functioning } \\
\text { Dead }\end{array}$ \\
\hline HL-A incompatibility & $\begin{array}{l}\mathrm{I} \\
\mathrm{J} \\
\mathrm{K} \\
\mathrm{L} \\
\mathrm{M} \\
\mathrm{N} \\
\mathrm{O} \\
\mathrm{P}\end{array}$ & $\begin{array}{l}\text { T.D.F. + E.C.I. } \\
\text { T.D.F. } \\
\text { T.D.F. } \\
\text { T.D.F. + A.L.G. } \\
\text { T.D.F. + A.L.G. } \\
\text { T.D.F. + E.C.I } \\
\text { T.D.F. + E.C.I. } \\
\text { T.D.F. + A.L.G. }\end{array}$ & $\begin{array}{l}1 \\
1 \\
3 \\
3 \\
1 \\
0 \\
1 \\
1\end{array}$ & $\begin{array}{l}\text { Functioning } \\
\text { Functioning } \\
\text { Functioning } \\
\text { Rejected } \\
\text { Dead } \\
\text { Functioning } \\
\text { Rejected } \\
\text { Functioning }\end{array}$ \\
\hline
\end{tabular}

T.D.F. $=$ Thoracic duct drainage. $\quad$ E.C.I $=$ Extracorporeal irradiation. A.L.G. $=$ Antilymphocytic globulin.

two of the four HL-A compatible and in seven of the eight HL-A incompatible patients despite these measures. In two of the incompatible patients rejections were severe enough to require graft removal, while a third patient developed septicaemia during a rejection crisis and died. Thus in this relatively small series of patients strong histocompatibility barriers could not be overcome with additional immunosuppressive measures.

\section{Incidence of Postoperative Morbidity}

Principally because of the hazards of immunosuppression, many transplant patients develop serious complications during their postoperative course. We attempted to assess the degree of postoperative morbidity in these three groups of patients from the duration of their hospital stay after transplantation, and from the number of subsequent admissions after the initial discharge. The mean hospital stay after grafting in the eight $\mathrm{HL}-\mathrm{A}$ compatible (38.5 days) and in the $18 \mathrm{HL}-\mathrm{A}$ incompatible (38.3 days) patients was more than twice that in the $11 \mathrm{HL}-\mathrm{A}$ identical patients (18.2 days). Seven of the 11 HL-A identical patients could be discharged from the hospital within 14 days and four others between 20 and 47 days. In contrast, only two of the eight HL-A compatible patients were discharged within 14 days and six between 26 and 97 days. Among the HL-A incompatible patients five could be discharged within 14 days and 10 between 15 and 60 days. Three other patients either rejected their grafts or died while still in the hospital. The difference between the HL-A identical and HL-A incompatible grafts is statistically significant $(\mathbf{P}<0.05)$. That between HL-A identical and HL-A compatible grafts fell short of statistical significance $(P=0.05$ to 0.08 ) while that between HL-A compatible and HL-A incompatible grafts was not significant $(P>0.8)$.

After initial discharge only 1 of the 11 (9\%) HL-A identical patients had to be readmitted for late complications (ureteric stenosis) compared with 7 of the $26(27 \%)$ HL-A compatible and incompatible patients (mostly for sepsis and/or rejections).

\section{Discussion}

These findings indicate that prospective leucocyte typing may be of considerable value in predicting the results of kidney transplantation in HL-A identical siblings. Within the period of follow-up HL-A identical transplants functioned earlier, required less immunosuppression, had less morbidity, and had no rejections. The single failure in this group directly followed surgical intervention for a non-immunological complication (ureteric stenosis), since the patient had enjoyed an entirely benign course right up to that time. Though sepsis also caused the failure of an HL-A compatible transplant, it developed de novo in a patient who had received intensive immunosuppression on three previous occasions for rejections, so that his average daily dose of prednisone during the followup period was one to five times as high as that of the HL-A identical patient who died. Our results suggest that in view of the increased risk of sepsis in immunosuppressed patients it might well be possible to decrease immunosuppressive therapy after a couple of months in highly-matched sibling donor transplants so that the hazards of infection may not occur. This might even be true of the problems of wound healing.

That less immunosuppression may suffice in HL-A identical sibling transplants is supported by the fact that in two patients cholestatic hepatitis forced us to discontinue azathioprine for variable periods of time. One patient, now seven months post-transplant, has been off azathioprine completely for the past 164 days and has been maintained solely on $0.43 \mathrm{mg}$. of prednisone per $\mathrm{kg}$. per day. Another patient has had two episodes of hepatitis during the second and fifth postoperative months, lasting 32 and 38 days, respectively, during which periods she was maintained on prednisone alone in a dose of 0.6 and $0.36 \mathrm{mg} . / \mathrm{kg}$. per day. Neither of these patients had shown any deterioration in graft function despite progressive reduction of prednisone dose.

In contrast to HL-A identity, HL-A compatibility did not correlate as well with the clinical results. This is not surprising when one considers that many $\mathrm{HL}-\mathrm{A}$ antigens are yet undetected so that a compatible graft may in fact be incompatible for one or more undetected antigens (Rapaport and Dausset, 1969). This possibility is less likely if compatibility was assigned on the basis of genotyping rather than phenotyping. Nevertheless, provided they survive the so-called high-risk period (Terasaki et al., 1967), HL-A compatible and identical grafts appear to do equally well while the HL-A incompatible grafts show a progressive attrition in numbers from chronic, irreversible rejection. 
The observation that many recipients clearly incompatible for the defined HL-A antigens also had a prolonged benign course-that is, no rejections-is consistent with the findings of Terasaki et al. 1967) and of Dausset et al. (1968) and additionally emphasizes the lack of complete correlation between HL-A matching and clinical course. The reasons for this discrepancy are likely to be complex, including the inherent immunological competence of the recipient and the effect of uraemia, his response to immunosuppressive drugs, the immunogenicity of the antigens in question, and whether or not the antigens cross-reacting with the incompatible donor antigens are present in the recipient (Kissmeyer-Nielsen et al, 1968). The fact that HL-A identical grafts showed a superior function even within the first two weeks of transplantation is not without interest, since authorities (Terasaki et al., 1966; Rapaport et al., 1967) have tended to emphasize only the late correlates of typing. Though a correlation exists between the immediate function of the graft and the duration of warm ischaemia (Carroll et al., 1969), this does not appear to hold as well with warm ischaemia times of less than an hour (Belzer et al., 1970). The range of total ischaemia time in these patients was 22 to 39 minutes. Because, however, of the many variables (some unknown) involved in the early function of the graft it is not possible to attribute this superior result to histocompatibility matching per se.

Though admittedly the period of follow-up for the HL-A identical patients was much shorter than that for the HL-A compatible and incompatible patients, the completely benign course shown by these patients over comparable periods of time is impressive. A longer follow-up should be especially interesting, since skin grafts exchanged between unmodified HL-A identical siblings are eventually rejected after a mean survival of 23 days in contrast to 11 days in the control group (Amos and Bach, 1968). Evidently, in the case of the skin minor non-HL-A antigen systems can exert their influence after a prolonged interval. It remains to be seen whether this will be the case also in HL-A identical kidney transplants under immunosuppression, especially in the light of the differences in immunological behaviour between skin and kidney transplants in experimental animals (Sakai et al., 1969).

We are indebted to Drs. J. P. Merrill, J. E. Murray, R. E. Wilson, and A. G. Birtch for their suggestions and encouragement. The transplants reported in this paper were performed by Drs. J. E. Murray, J. H. Harrison, R. E. Wilson, and A. G. Birtch. The statistical analyses were done by Dr. John Atkinson, of the Harvard Computing Facility.

This work was supported by grants AI-06091 and AI-04606 from the U.S. Public Health Service, and by grants from the United States Army Research and Development Command, from the Atomic Energy Commission, and from the John A. Hartford Foundation.

\section{REFERENCES}

Amos, D. B., and Bach, F. H. (1968). Fournal of Experimental Medicine

Amos, D. B., and Zmijewski, C. M. (1967). Proceedings of the Third International Congress of Nephrology, Washington, D.C., 1966, ed. G. E. Schreiner, p. 341. Basel, Karger.

Belzer, F. O., Reid, T. W., Pryor, J. P., Kountz, S. L., and Dunphy, J. E. (1970). Surgery, Gynecology and Obstetrics, 130, 467 .

Carpenter, C. B., and Merrill, J. P. (1969). Archives of Internal Medicine, 123, 501 .

Carroll, R. N. P., Chisholm, G. D., and Shackman, R. (1969). Lancet, 2, 551

Dausset, J., Rapaport, F. T., and Legrand, C. (1968). In Advance in Transplantation, ed. J. Dausset, J. Hamburger, and G. Mathe, p. 749. Baltimore, Williams and Wilkins.

Hume, D. M., et al. (1966). Annals of Surgery, 164, 352.

Kissmeyer-Nielsen, F., Svejgaard, A., and Hauge, M. (1968). Nature, 219, 1116.

Lee, H. M., Hume, D. M., Vredevoe, D. L., Mickey, M. R., and Terasaki, P. I. (1967). Transplantation, 5, 1040.

Murray, J. E., et al. (1968). Annals of Surgery, 168, 416.

Patel, R., Mickey, M. R., and Terasaki, P. I. (1969). British Medical fournal,

2, 424.
Rapaport, F. T., and Dausset, J. (1969). Progress in Cardiovascular Diseases, $12,119$.

Rapaport, F. T., et al. (1967). Annals of Surgery, 166, 596.

Sakai, A., Simonsen, M., and Jensen, E. (1969). Transplantation, 7, 444.

Starzl, T. E. (1964). Experience in Renal Transplantation, p. 130. Philadelphia, Saunders.

Terasaki, P. I., et al. (1966). Annals of the New York Academy of Sciences, 129,500 .

Terasaki, P. I., and McClelland, J. D. (1964). Nature, 204, 998.

Terasaki, P. I., Vredevoe, D. L., and Mickey, M. R. (1967). Transplantation,

5, 1057 .
Tilney, N. L., Atkinson, J. C., and Murray, J. E. (1970). Annals of Internal Medicine, 72, 59.
- Consultant Physician in General Medicine, Eastern General Hospital, Edinburgh EH6 7LN

† Registrar in General Medicine, Royal Infirmary, Edinburgh 3.

F Medical Superintendent, Astley Ainslie Hospital, Edinburgh EH9 2HL.

Consultant Physician in Diabetic and Dietetic Department, Royal Infirmary, Edinburgh 3.

\section{Introduction}

Starvation is an effective method of losing weight but is justified only if it produces a lasting effect. We report the results of this treatment in 25 patients with refractory obesity who agreed to be starved in hospital until they had reduced to within $25 \%$ in excess of their ideal weight.

\section{Patients and Methods}

Fourteen women and 11 men were selected (see Table). All had gross refractory obesity (Duncan et al., 1960), had previously failed to respond to other forms of treatment, and were apparently anxious to starve in hospital until they had attained an acceptable weight. Most were admitted to a rehabilitation centre, where they were encouraged to use fully the various facilities available. They were allowed to drink as much water, black coffee, tea, and acaloric fruit juice as they wished; however, a low-calorie carbohydrate-restricted meal was given if specifically requested. Many took one such meal a week, but the emphasis was on trust rather than super- 